\title{
Alunos de Psicologia e a Educação para a Morte
}

Psychology students and death

Alumnos de Psicología y la educación para la muerte
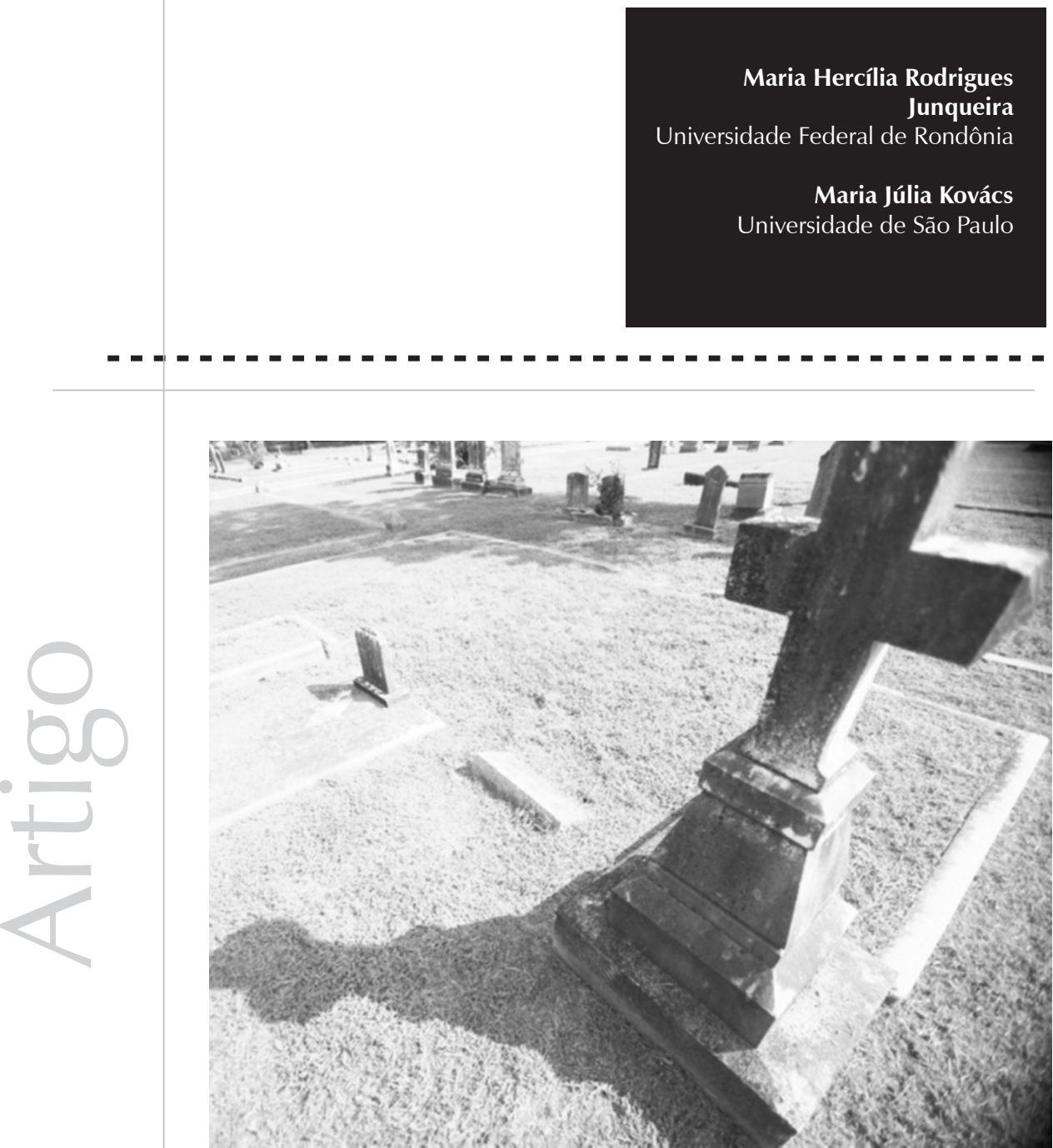
Resumo: Em 2003, foi realizada uma pesquisa com 23 alunos do 7o período do Curso de Psicologia da Universidade Federal de Rondônia. Os principais objetivos foram: verificar como estão sendo tratados a morte e o morrer no Curso de Psicologia pelos professores e compreender como os alunos vêem essa temática. Buscar o entendimento dessas questões poderia propiciar uma ampliação dos assuntos tratados no curso e trazer maiores informações aos discentes. Aplicou-se um questionário com cinco perguntas abertas, e os resultados demonstraram que os alunos não se sentem preparados para lidarem com a morte, que o tema é abordado superficialmente em disciplinas de outras áreas e que eles se sentem indignados pela falta de informação proporcionada pela grade curricular. O embasamento teórico-prático possibilita maior segurança para lidarem com a morte, o que poderá vir a ser corrigido por meio de uma mudança na postura dos professores e pela inclusão de disciplinas específicas que abordem o tema da morte e do morrer.

Palavras-chave: Ensino da morte. Alunos de Psicologia. Psicologia. Morte.

Abstract: In 2003 a research was conducted with 23 students of the 7 th. of the Psychology Course at the Federal University of Rondonia (Brazil). The main objectives were: verify how the issues about death and dying are being dealt with by the professors of this course and also understand students' view of that issue. Seeking the understanding of this matter could amplify the teaching about the subject concerning of death and dying, a questionnaire with 5 open questions was used with the students. The answers demonstrated that the students felt they weren't prepared to cope with death, the subject is presented superficially in some disciplines, they are upset with the lack of information offered by the curriculum concerning to studies about death. The theoretical foundations could offer security to deal with death which would be improved if the professors were interested in changing their posture toward the issue of to death, including specific issues concerning death and dying.

Keywords: Death education. Psychology students. Psychology. Death.

Resumen: En 2003, fue realizada una pesquisa con 23 alumnos del 7o período del Curso de Psicología de la Universidad Federal de Rondônia. Los principales objetivos fueron: verificar como están siendo tratadas la muerte y morir en el Curso de Psicología por los maestros y comprender como los alumnos ven esa temática. Buscar el entendimiento de esas cuestiones podría propiciar una ampliación de los asuntos tratados en el curso y traer mayores informaciones a los discentes. Se aplicó un cuestionario con cinco preguntas abiertas, y los resultados demostraron que los alumnos no se sienten preparados para que tratar con la muerte, que el tema es abordado superficialmente en disciplinas de otras áreas y que ellos se sienten indignados por la falta de información proporcionada por las asignaturas curriculares. La base teoréticopráctica posibilita mayor seguridad para que traten con la muerte, lo que podrá venir a ser corregido por medio de un cambio en la postura de los maestros y por la inclusión de disciplinas específicas que aborden el tema de la muerte y del morir.

Palabras-clave: Enseñanza de la muerte. Alumnos de Psicología. Psicología. Muerte.

Falar em educação para a morte nos remete à dificuldade de enfrentamento e superação do medo da morte pelos profissionais da área da saúde. Esse é um tema polêmico, porque lida com questões pessoais relacionadas à finitude da existência humana. Parece mais fácil desconhecer e negar a morte do que ter que encará-la e enfrentá-la.

A dificuldade em lidar com a morte, por parte dos profissionais de saúde, é analisada por Hennezel e Leloup (2001) como uma conseqüência do afastamento das grandes tradições que preparavam as pessoas para o momento final, ajudando a todos a decifrar o sentido de suas existências. A sociedade atual, segundo Ariès (1990), expulsou o culto à morte, mantendo-o apenas para as pessoas famosas e importantes. Um muro foi levantado em torno da morte, o que acaba contribuindo para uma formação inadequada de profissionais, principalmente da área da saúde, que, em alguns casos, apresentam uma postura fria e inacessível diante de uma pessoa que esteja no final da vida.

Diante desse quadro de temor da morte, pesquisadores verificaram a necessidade de 
se oferecerem cursos que abordem o tema da morte e do morrer. Esse movimento de reintroduzir a morte no campo da consciência e do pensamento, de acordo com Hennezel e Leloup (2001), permite aos profissionais da saúde enfrentá-la humanizando as instituições.

Mais de 100 cursos didáticos, experienciais ou mistos, foram identificados por Durlak e Riesenberg (1991) e citados por Kovács (2002), até o ano 1970, nos Estados Unidos. Os cursos que incluem programas vivenciais permitem que os participantes examinem seus sentimentos e preocupações com relação à morte e o morrer, utilizando-se o role-playing e a dramatização. Esses cursos incluíam visitas a cemitérios, cuidados a pacientes terminais, confecção do próprio atestado de óbito e exercícios com fantasias de morte.

A autora relata ainda que, de acordo com Kastenbaum e Costa (1997), os temas desenvolvidos nos cursos sobre a morte e o morrer abordavam o desenvolvimento emocional e cognitivo dos participantes e suas atitudes frente à morte, os pacientes terminais e os processos de morrer, os suicídios, lutos, perdas e a morte ligada a comportamentos e estilos de vida.

A questão da morte era escassamente abordada nas salas de aula dos cursos universitários, formadores de futuros pesquisadores e profissionais, conforme verificaram Kastenbaum e Aisenberg (1983). Esses autores observam que uma disciplina anual sobre Psicologia do Desenvolvimento, pertencente a um curso de graduação de quatro anos, não incluía quase nada sobre a íntima relação entre crescimento e morte. Observaram que a psicodinâmica da morte raramente era abordada no curso como um todo, e que deveria ser considerada para todas as faixas do desenvolvimento.

Até o ano 1985, havia no Brasil um curso de especialização oferecido por Wilma Torres, inicialmente pelo Instituto Superior de Estudos e Pesquisas Psicossociais-ISOP, e, posteriormente, com o fechamento deste, pela Universidade Federal do Rio de Janeiro (Kovács, 2002). A autora destaca ainda que, na formação do psicólogo, há pouco espaço para reflexões sobre o tema da morte, embora já existam algumas iniciativas em nível de graduação, pós-graduação e extensão. Atualmente, esses números vêm aumentando significativamente, provavelmente relacionados aos grandes desastres, nos quais a morte violenta é intensamente veiculada pela mídia.

Observa-se que a inserção do tema da morte na formação do psicólogo é importante porque, como profissional da área de saúde, ao lado de médicos e enfermeiros, a morte passou a fazer parte de seu cotidiano profissional. Nas escolas, há a necessidade de abordar o tema da morte, sendo exigida essa preparação do psicólogo escolar. No âmbito familiar, a perda de uma pessoa significativa ou de um animal de estimação demanda cuidados, especialmente com crianças. No contexto organizacional, o psicólogo vê-se frente à morte nos acidentes de trabalho e nas tentativas de suicídio, situações que necessitam de intervenção psicológica.

Na prática clínica, o psicólogo precisa estar preparado para identificar processos mórbidos ou autodestrutivos presentes nas atitudes, nem sempre conscientes, de seus pacientes. Nos processos de enlutamento, nas chamadas "pequenas mortes", como postulado por Kovács (1996), as perdas ou separações de pessoas significativas ou aquelas que 
O processo de acolhimento de pacientes gravemente enfermos realizado por profissionais constitui um processo de rehumanização da morte que passou a ser interditado nos séculos $X X / X X \mid$,

Ariès (1977). envolvem processos de mudanças de vida necessitam de acompanhamento psicológico ou de psicoterapia. A atuação junto a idosos é outro campo de trabalho para os psicólogos, pelas dificuldades psíquicas e sociais ligadas ao envelhecimento e pelo fato de estarem, pela idade, mais próximos da morte.

Numa pesquisa realizada com psicólogos que atuavam junto a pacientes em fase terminal, Tonetto e Rech (2001) encontraram algumas diretrizes que envolviam práticas frente à morte e o morrer. O psicólogo deveria permitir que o paciente falasse de si mesmo, da sua morte, ouvindo suas necessidades, além de estar disponível para tocá-lo e para aprender com ele. Verificaram que é fundamental acolher a pessoa doente, ser continente, dar apoio, trabalhar questões espirituais, ajudar nas despedidas da vida e das pessoas que ama, buscar o apoio da família, auxiliar no seu desligamento da vida material e na aceitação da morte. O respeito aos desejos e opções e a postura de aceitação do inevitável por parte do profissional são atitudes fundamentais para que a pessoa possa morrer com dignidade.

O processo de acolhimento de pacientes gravemente enfermos realizado por profissionais constitui um processo de rehumanização da morte que passou a ser interditado nos séculos XX/XXI, como postulou Ariès (1977). Segundo a representação da morte domada (nome dado pelo autor), a morte era considerada um processo natural da vida, e a pessoa à morte ficava em casa com a família presente e podia se despedir dos entes queridos. Havia a possibilidade de reconciliações, de reorganização de atividades práticas e de preparação para o morrer. A tranqüilidade diante da morte possibilita que a pessoa entre em ressonância com o Cosmos, como afirma Weil (1989), e, nessa concepção, a morte é vista apenas como uma passagem para uma outra espécie de existência, podendo o medo ser enfraquecido diante desse fato.

Apesar de a morte sempre fazer parte da vida de todas as pessoas, essa pode não encontrar representação nítida no processo mental, devido ao fato de esse ser um processo de vida desconhecido e de não haver modo de se aprender a enfrentar a morte a não ser por intermédio dos livros. O que pode ocorrer são reflexões sobre as relações pessoais com a vida e com a morte e o contato com variadas situações relacionadas com a morte e o morrer, conforme Kastenbaum e Aisenberg (1983).

\section{Objetivos}

Este trabalho teve como objetivos verificar como está sendo tratado o estudo sobre a morte e o morrer no Curso de Psicologia da Universidade Federal de Rondônia e compreender como os seus alunos lidam com a temática da morte e do morrer.

O entendimento dessas questões poderá contribuir para a inclusão do tema da morte na graduação em Psicologia da UNIR.

\section{Método}

Esta pesquisa de abordagem qualitativa contou com 23 alunas e alunos do 7 o período do Curso de Psicologia da Universidade Federal de Rondônia, criado em 1989, localizado na cidade de Porto Velho/RO. A escolha dos participantes se relacionou ao fato de eles terem de participar, em breve, dos estágios curriculares, sendo necessário que adquiram uma visão mais abrangente do currículo oferecido. 
Os dados foram colhidos por meio de questionário aberto, com questões progressivas, coerentemente articuladas e com uma linguagem simples e inteligível aos participantes, como é proposto por Chizzotti (1998). Optou-se por questões abertas, que proporcionam liberdade de resposta aos participantes.

A análise e a compreensão dos depoimentos envolveram a leitura e a releitura das respostas dos alunos, buscando-se desvendar o seu significado bem como a identificação dos elementos significativos a partir dos temas que mais se repetiram. Para tanto, baseamonos na proposta de Rogers (1987, 1989, 1991) de busca dos elementos significativos na fala dos alunos participantes. Foram realizadas várias escutas das gravações e releituras do material impresso, na tentativa de assimilar todas as informações referentes às perguntas realizadas, de apreender, nos depoimentos, as falas referentes à morte e ao morrer, e, finalmente, de buscar a repetição dos elementos para agrupá-los em categorias temáticas significativas.

A pesquisa de textos de outros autores para a compreensão do processo de morte e do morrer facilitou a compreensão das respostas dadas pelos alunos. A identificação dos participantes (P) foi omitida, e os questionários foram numerados de 1 a 23 para facilitar a análise.

\section{Aspectos éticos}

Os alunos foram consultados se queriam ou não participar da pesquisa, tendo assinado o Termo de Consentimento Livre e Esclarecido. Garantiu-se o anonimato, combinando-se com os alunos que os dados seriam tratados coletivamente, de forma a não poderem ser reconhecidos por outras pessoas.

Após a realização da pesquisa, será feita uma devolutiva aos alunos e, a partir das suas opiniões expressas, serão propostos espaços de discussão sobre a morte para os alunos da Universidade Federal de Rondônia.

\section{Apresentação dos dados obtidos - temáticas principais}

\author{
O Curso de Psicologia e o
}

ensino da morte e o morrer

Não se fala sobre a morte

\begin{abstract}
P6: Até este momento, as questões da morte não foram faladas e nem entraram na dinâmica de nenhuma disciplina.

P8: Estando no $7^{\circ}$ período, posso estar errado, mas esse tema nunca foi tratado até este momento. ...se falaram no curso sobre a morte, eu faltei nessa aula.

P23: Ainda não vi nada no Departamento que verse sobre o tema em sua totalidade (curso, debate, seminário ou coisa do gênero).

P11: ...temos as disciplinas de Filosofia e Desenvolvimento III, que falam sobre a velhice e a morte; fora isso, mais nada.
\end{abstract}

A maioria dos alunos concordou que não se fala sobre morte e o morrer no Curso de Psicologia, que as questões da morte não entraram no programa de nenhuma disciplina. Quase todos lembraram que estão no 7o período do curso e que ainda não receberam nenhum tipo de preparo para tratar das questões da finitude humana. O assunto só é abordado pelos professores quando algum aluno questiona sobre determinado fato veiculado pela mídia.

Relataram que há um enfoque superficial sobre a morte, pois somente algumas disciplinas, como Antropologia e Sociologia, que não pertencem ao Departamento de Psicologia, trataram a temática da morte.

De um modo geral, os alunos demonstraram seu descontentamento pela falta de informação 
sobre o tema, pontuando a defasagem na grade curricular do Curso de Psicologia. Cabe ao aluno a responsabilidade de ir em busca de informação e compreensão sobre a morte, elaborando suas perdas significativas ou procurando participar em algum curso fora do âmbito da Universidade.

Apresentaram também um sentimento de descrédito e desesperança com relação ao Curso de Psicologia quanto à preparação para a temática da morte e do morrer. Uma aluna pontuou que ninguém é eterno, e que a morte é uma conseqüência natural da vida. Lembra Kübler-Ross (1979), que propõe que a preparação sobre a morte e o morrer deve começar com as crianças e os jovens, para que aprendam a encarar a realidade da morte.

Textos sobre a morte e o morrer deveriam ser estudados nas disciplinas de Psicologia do Desenvolvimento I, II e III, Psicologia Escolar e Problemas de Aprendizagem I e II, Psicologia Hospitalar, Psicologia Comunitária, Psicologia Social e Técnicas de Aconselhamento Psicológico.

Parece haver uma negação da morte no currículo do Curso de Psicologia. É preciso considerar que se está preparando profissionais para o mercado de trabalho, no qual estarão em contato constante com a morte, nos consultórios, hospitais, escolas ou nas empresas. A negação e a repressão da morte, para Kovács (2003), são mecanismos de proteção, porque permitem que se viva em um mundo de fantasia no qual a imortalidade se faz presente. A negação surge como uma defesa para não se entrar em contato com essa fragilidade universal. Parece ser mais fácil não falar sobre a morte do que ter que encarar a própria finitude.
A reflexão sobre a morte como uma outra face do nascimento é apontada por Crema (2001) como parte fundamental dos programas educacionais, desde o início. O autor considera grave essa lacuna, que se estende até a formação dos profissionais de saúde, que passam a exercer a profissão completamente despreparados, principalmente para o acompanhamento de pessoas nas fases terminais da existência.

Um outro aspecto importante a ser questionado é com relação ao despreparo dos professores em lidarem com um tema tão polêmico, controvertido e difícil de resolver.

\section{Os professores do Curso de Psicologia e a educação para a morte}

Dificuldade dos professores

P10: Simplesmente a ignoram. Talvez por não estar incluída nos programas das disciplinas, ou pela falta de interesse nosso.

P13: ...fala-se dos choques das perdaslutos que podem desencadear processos depressivos, surtos neuróticos e psicóticos, mas foi pouco o esclarecimento...

P14: Mas o que já ouvi sobre o assunto é que devemos amenizar esse processo, esse é o nosso papel.

Quanto à postura dos professores do Curso de Psicologia, do ponto de vista dos alunos, os resultados foram parecidos com o da questão anterior: a maioria não aborda a questão da morte, e quando o faz, é superficialmente. Os alunos ressaltam que não são oferecidas informações sobre a morte e o morrer, por isso baseiam-se nas suas próprias experiências. Na graduação 
Falar sobre a morte é tão urgente quanto viver a vida. É preciso criar espaços nos quais se possa encontrar a solidariedade e a ajuda para enfrentar a própria morte ou a de uma pessoa significativa.

Hennezel e Leloup (2001). em Psicologia, as únicas disciplinas que abordam o tema da morte são as disciplinas Psicologia da Personalidade, que enfoca a questão da pulsão de vida e pulsão de morte, e Psicologia do Desenvolvimento III, que aborda a associação velhice-morte. A morte, como fenômeno psicológico, é ignorada pelos professores, que não oferecem esclarecimentos sobre o que significa estar próximo à morte ou ter vivenciado a perda de alguém significativo. Pode ser que desconheçam a bibliografia a respeito dessas questões ou temam entrar em contato com a finitude da vida.

Breves referências ao suicídio surgiram somente após questionamentos de um aluno; outro observou que alguns professores, ao falarem sobre o tema da morte, o fazem abordando assuntos polêmicos como aborto, suicídio ou eutanásia. Outros professores apresentaram questões religiosas e morais.

A morte passou a ser invertida, solitária e cheia de sofrimento, tendo deixado de ser um evento familiar, como observa Ariès (1990), o que traz prejuízos à qualidade de vida da pessoa e de sua família. A morte passou a ser clandestina, estabelecendose assim uma nova relação com o morrer. Passou-se a representar uma comédia, fingindo-se que nada mudou e mantendose o doente na ignorância para que ele não sinta o morrer, ao contrário do que acontecia anteriormente, quando a pessoa sentia e vivenciava a morte se aproximando. Era importante para todos!

A situação se inverteu, e a pessoa que está à morte se coloca na dependência de seus familiares. O processo do luto também sofreu transformações, como se fosse proibido expressar os sentimentos pela dor da perda. A importância de se vivenciarem as etapas do luto, de modo singular e próprio, é enfocada por Bowlby (1985) como importante para que a pessoa possa reorganizar a vida, para ir depois retornando às atividades com uma boa lembrança do ente perdido, o que diminui seu pesar.

Segundo Crema (2001), tudo aquilo que se nega pode se tornar inconscientemente traiçoeiro e transformar-se num pesadelo sintomático, permeando uma vida de horrores e subtraindo da consciência a transitoriedade e finitude. A interdição da morte provoca angústias, como apontam Hennezel e Leloup (2001). Falar sobre a morte é tão urgente quanto viver a vida. É preciso criar espaços nos quais se possa encontrar a solidariedade e a ajuda para enfrentar a própria morte ou a de uma pessoa significativa.

É importante observar que a grade curricular do curso de Psicologia em questão não favorece o contato de professores e alunos com a morte e o morrer. Isso demonstra o despreparo para lidar com as questões profissionais e pessoais em relação ao tema.

\section{Como se preparar para lidar com a questão da morte no contexto da graduação em Psicologia}

Disciplinas, atividades

extracurriculares e teórico-práticas

P3: Deveríamos ter mais disciplinas voltadas para o assunto, que é tão rico, mas, ao mesmo tempo, é um grande mistério.

P22: Disciplina que abordasse o assunto, assim como abordam a vida e o desenvolvimento.

P10: Cursos, palestras, especialistas da 
área, informações de trabalhos práticos, pesquisas.

P21: Através de aulas práticas nas instituições hospitalares, com uma teoria que pudesse dar subsídio para tanto.

Os alunos demonstraram o desejo de que houvesse mudanças na trajetória do curso. Afirmam a necessidade de se ter disciplinas específicas voltadas para o tema da morte e do morrer. As disciplinas optativas seriam uma alternativa para aprofundar a temática da morte da mesma forma que se fala da vida e do desenvolvimento humano. Acreditam que, havendo um pouco mais de embasamento teórico, sentir-se-iam mais seguros para lidarem com a morte.

Sugeriram que fossem oferecidas outras atividades além das disciplinas, como cursos, palestras, pesquisas, discussões e indicações de leituras. Lembraram a importância das atividades fora do âmbito da Universidade nos estágios, nas quais poderiam vivenciar a dor das pessoas sob seus cuidados e aprender como tratá-la. Várias teorias poderiam dar subsídios para essa experiência.

Para criar cursos sobre a morte e o morrer, Kovács (2002) propõe que os objetivos sejam bem claros, enfatizando uma proposta pedagógica, e não psicoterapêutica. Esse fato é muito importante, porque muitos que procuram esses cursos podem estar vivenciando perdas, pensando em suicídio ou apresentando comportamentos autodestrutivos e podem estar buscando psicoterapia. Questiona-se se os cursos provocam modificações na vida dos participantes. Mudanças são graduais e contínuas, e os cursos podem promover a sensibilização em relação ao tema, levando à reflexão sobre o que está sendo abordado. Reafirma-se que não se pode perder de vista o enquadre pedagógico.

A herança cultural, a educação ou os treinamentos específicos não são os únicos suportes para se entender o lugar da morte na vida das pessoas. Kastenbaum e Aisenberg (1983) observam que a formação educacional não é o único guia nesse processo, e é muito importante que os psicólogos usem a experiência das perdas vividas para aprender de forma significativa como lidar com a morte, o morrer e o luto.

Alguns tabus já estão sendo superados, segundo Hennezel e Leloup (2001), e a noção de acompanhamento terapêutico do paciente terminal começa a se tornar uma prática mais freqüente para os profissionais da área da saúde. Muitos estão se conscientizando de que acompanhar uma pessoa amiga às portas da morte, em seus momentos finais, é uma tarefa que cabe a todos, é uma questão de solidariedade. Não deixá-la sozinha nesse momento de transição é estar do seu lado, segurando sua mão, sendo um guia pelos caminhos desse mundo desconhecido.

\section{Desesperança com relação ao curso}

P15: ...não vejo que o curso me preparará para ela (morte), ou melhor, para lidar com o tema.

P17: Gostaria que o curso me ajudasse a compreender os sentimentos e os conflitos que vivenciam os pacientes terminais e a família. ...Entender como eu lido com essa questão.

Os alunos demonstraram não ter esperança de que o seu curso de Psicologia possa prepará-los para lidar com a morte e o morrer. Essa postura pode estar relacionada com o 
fato de estarem concluindo o $7^{0}$ período, faltando cursar a disciplina Psicologia Hospitalar, na qual se abordará o tema da morte e do morrer, estando aí depositadas as suas expectativas nessa matéria.

Os profissionais de saúde, especialmente os médicos e os enfermeiros, passam por cursos de formação que enfatizam os procedimentos técnicos em detrimento de uma postura mais humanista, o que leva a uma não sensibilização em relação à morte, como pontua Kovács (2002). O mesmo ocorre com os cursos de Psicologia, cujos alunos se ressentem também da falta de preparo para lidar com as pessoas que estão próximas da morte.

No curso do Instituto de Psicologia da Universidade de São Paulo, é oferecida uma disciplina optativa, para todos os alunos da área da saúde, que Ihes proporciona um espaço na sua formação no qual possam explorar e aprofundar o tema da morte (Kovács, 2002). Uma proposta semelhante poderia ser criada no Curso de Psicologia da Universidade Federal de Rondônia, o que atenderia as inquietações e indagações dos alunos e enriqueceria a grade curricular.

\section{Como é estar preparado para a morte}

Dificuldade em se preparar para a morte e aceitação do morrer

P2: Acredito que esse preparo é um pouco complicado........mas, no fundo, você nunca está preparado totalmente para encarar a perda de alguém querido. É difícil a perda! P11: Acredito que nunca há esse preparo. É um amadurecimento gradual, um processo.

P1: Quando o assunto não causa mais tanto pânico e consternação.... ...Também estamos preparados quando aceitamos a morte como algo que é inevitável.
P7: É ver como algo natural, que faz parte da evolução da vida, é saber vivenciar o luto de maneira saudável.

Alguns alunos sentem dificuldades em se preparem para a morte, em trabalharem com as suas perdas. Crêem que esse aprendizado seja um processo gradual e contínuo que acontece nas vivências com os doentes e vem das contribuições da parte teórica, assim poderão lidar com a morte e amenizar a dor e o sofrimento dos familiares e do paciente.

Outros acreditam na aceitação da morte como algo inevitável que faz parte da evolução da vida, essencial para lidar com a terminalidade. A visão que se tem da morte como fim, como renascimento ou como solução irá contribuir para essa preparação. Pensar sobre a morte como um momento da pessoa resgata a morte natural, como relatada por Ariès (1990).

O modo como se conceitua a morte pode ser influenciado pelo momento em que se vivencia a situação experienciada, surgindo um tipo de cognição da morte, entre tantos outros que se conhece, o que estimularia novos conceitos ou modificaria as concepções já existentes, como apontam Kastenbaum e Aisenberg (1983).

Os hospitais, nos dias de hoje, não estão preparados para acolher, lidar e acompanhar as pessoas que têm doenças incuráveis, como observam Hennezel e Leloup (2001). É a partir das aflições dos profissionais de saúde perante o sofrimento dos pacientes e de suas famílias que surgem os questionamentos, a exigência de uma formação específica e a necessidade de também serem apoiados nessa árdua tarefa. 


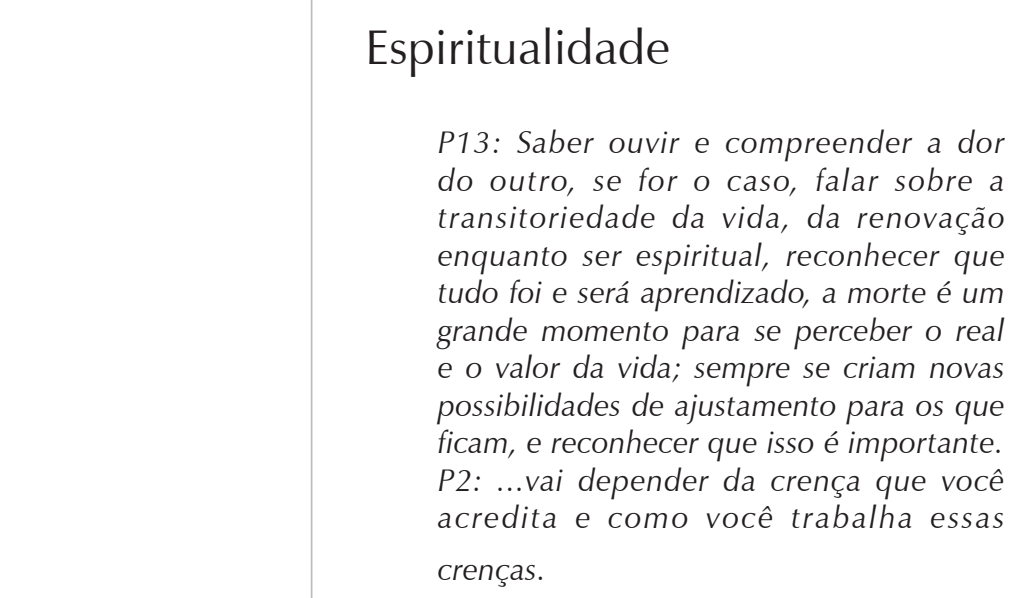

É necessário ter uma crença, religiosa ou científica, que explique o ser e a sua existência no mundo.

Zaidhaft (1990). o medo da morte. As maturidades humana, pessoal e religiosa têm, para Imara (1996), o mesmo significado e podem ser medidas pelo grau de comprometimento que a pessoa tem com essa forma de intercâmbio humano.

Pensar na finitude é algo assustador e insuportável, por isso é necessária certa dose de negação da morte, uma quase certeza, uma fé ou esperança de que não nos atingirá, pois só assim se pode sobreviver, de acordo com Zaidhaft (1990). É necessário ter uma crença, religiosa ou científica, que explique o ser e a sua existência no mundo. A fé religiosa, para Imara (1996), é importante para a pessoa evoluir criativamente e transformar sua vida, enfrentando os dissabores diante da morte, independentemente de qual seja o real conteúdo da sua fé.

As famílias perderam também a capacidade de falar aberta e livremente sobre as questões espirituais. Segundo Hennezel e Leloup (2001), deixa-se que a escolha desse saber seja feita pela própria criança quando se torna adulto. No local de trabalho, predomina a lei do silêncio, no qual assuntos como a espiritualidade, a transcendência e a vida após a morte, entre outros, não podem ser debatidos.

Na pesquisa junto a profissionais que lidavam com pessoas em estágio terminal, Tonetto e Rech (2001) verificaram que a religiosidade e a espiritualidade são auxiliares para o enfrentamento da morte. Crema (2001) vê a morte como a partida da jornada existencial e que vem, por vezes, acompanhada de torturante angústia e totalmente despida de delicadeza. O caráter do sagrado e de humanidade está distante dos processos contemporâneos do morrer. O autor considera que é preciso conspirar 
para a conquista de um clima de respeito, consciência e dignidade pelo momento da partida.

Acreditar que não há extinção total do ser com a deterioração do corpo serve de conforto para o profissional, o paciente e a família.

\section{Como é o preparo dos alunos para lidarem com a morte?}

Não se sentem preparados

P2: Acredito que não me sinto preparada ainda enquanto aluna...

P10: Acredito que hoje, e posso afirmar com extrema convicção, que não estou preparado...

P18: Não, é misterioso, traz medo. ...Como "pessoa", tenho a questão mais bem resolvida, mas não ao ponto de ajudar alguém a compreender e aceitar a morte. P20: ...não sei se saberia lidar com pessoas morrendo ao meu lado, pois não passei por tais experiências.

A maioria dos alunos não se sente preparada para lidar com as questões da morte e do morrer, mas acreditam que ainda haja tempo para amenizarem essa lacuna em seu aprendizado. A morte é vista como misteriosa e inesperada, provoca medo e evitar falar da mesma é uma forma de proteger-se. O sentimento de impotência diante da morte surge por se considerá-la inaceitável, apesar de esse ser um processo natural e o destino de todos. O medo de envolver-se emocionalmente com a situação, aliado à falta de informação, gera insegurança.

A experiência de ter passado por situações de perda é pontuada como a única forma que os alunos tiveram para aprender sobre a morte e o morrer; entretanto, no curso, não tiveram espaço para discutir a atuação profissional de ajudar alguém a compreender e a aceitar a morte. Acreditam que a Psicologia possua ferramentas (disciplinas, cursos, palestras, estágios) que possibilitarão melhor desempenho profissional.

Em seus dados de pesquisa, Tonetto e Rech (2001) verificaram que uma das maiores dificuldades encontradas pelos profissionais de Psicologia foi com relação às implicações emocionais, à ressonância interna ao lidar com o paciente terminal, por mais elaborados que estivessem os conflitos e lutos do terapeuta. Para poder lidar com essas emoções, é importante que o terapeuta esteja constantemente se revendo, passando por um processo psicoterápico.

A ideologia médica de não se envolver com o paciente, de ter sangue frio para lidar com situações de morte, também está presente nos cursos de Psicologia, nos quais ocorre a negação da morte (Zaidhaft, 1990).

\section{Sente-se pouco preparado}

P1: Eu me acho um pouco preparada...

P5: Como aluna do $7^{\circ}$ período, talvez não totalmente.

Os alunos destacam que o fato de se sentirem pouco preparados para lidar com a questão da morte está relacionado com a experiência pessoal trazida em psicoterapia, na qual puderam elaborar lutos passados.

A pesquisa de Tonetto e Rech (2001) aponta o que deveria ser o preparo para os psicólogos que trabalham com a morte e o morrer, a saber: um bom nível de autoconhecimento, constante auto-avaliação de seus aspectos emocionais, boa tolerância à frustração e ao inacabado, disponibilidade, saber lidar com o afeto, ser equilibrado emocionalmente, ter 
motivação e capacidade de se redimensionar internamente, apresentar maturidade teórica e fazer constante reciclagem. Portanto, como se vê, é necessário ter uma considerável bagagem interior.

Com relação ao setting terapêutico, verificaram que é preciso ter flexibilidade, maturidade e desprendimento e demonstrar interesse pelo paciente, vendo-o como uma pessoa que ainda tem vida, e, principalmente, saber lidar com o sentimento de impotência diante das limitações e das perdas. Por tudo isso se observa a importância da psicoterapia e do autoconhecimento.

Segundo Rogers (1983), se a função do psicólogo é estabelecer a comunicação entre o paciente, a família e a equipe de saúde, ouvindo o não dito, as metáforas, a linguagem simbólica, tudo aquilo que está subjacente ao que está sendo verbalizado, perguntamo-nos: como os alunos podem agir dessa forma se não receberam orientação quanto ao modo de proceder diante da morte? Por outro lado, como é possível prepará-los, se os próprios professores se sentem despreparados?

\section{Busca do preparo}

P2: ... acredito que é um processo contínuo e longo, e quem sabe, daqui um tempo, eu não me sinta um pouco mais preparada para lidar com esta tal de morte?

P3: Estou buscando esse preparo, pois é um tema que me fascina muito.

P4: Acredito que ainda há tempo para despertarmos para essa lacuna, que pode aparecer a qualquer momento em nossa vida profissional (seja onde quer que vá)

A busca pessoal surge como determinante para o aprendizado, graças à fascinação que o tema exerce. É um preparo que precisa ser construído para que se possa ter a firmeza necessária quando for preciso colocá-lo em prática.

Observa-se que há poucas referências que envolvam a formação de educadores e professores e as questões da morte, o que indica a necessidade de se propiciar um espaço no qual eles possam expressar suas emoções e sentimentos com relação ao tema e suas dificuldades diante das crianças e jovens que estão vivenciando perdas.

Para a formação do psicólogo, pode-se seguir uma proposta pedagógica que considere o tripé teoria, prática e desenvolvimento pessoal, num processo de aprendizagem significativa. É necessário haver um espaço de escuta, envolto numa atmosfera de confiança e respeito, no qual os participantes possam fazer um mergulho dentro de si mesmos, confrontar-se com seus próprios sentimentos e emoções e poder compartilhá-los com o restante do grupo sem críticas, julgamentos ou restrições.

Um dos papéis do profissional de saúde é o de ajudar a pessoa a morrer com dignidade, o que envolve um trabalho de apoio familiar, a identificação das necessidades e prioridades para que se possa estruturar o trabalho, com a intervenção, a mediação da relação paciente-família-equipe e a decodificação de suas mensagens (Tonetto \& Rech, 2001).

A busca do preparo deve ser constante, e nunca abandonada. O mergulho interior para o autoconhecimento é imprescindível para o bom desempenho do papel profissional, especialmente quando se lida com a questão da terminalidade. 


\section{Discussão}

Pelo que foi exposto pelos alunos, pode-se perceber que estão se formando como se não fossem lidar com a questão da morte, como se esta não fizesse parte das atividades profissionais do psicólogo. Revelam que os professores do Curso de Psicologia da UNIR não têm, no conteúdo programático de suas disciplinas, os temas referentes à morte e o morrer. O desejo dos alunos foi aliar a teoria à prática, poder vivenciar situações de morte e ter espaços de discussão e supervisão. Um outro aspecto importante questionado foi em relação ao despreparo dos professores em lidarem com esse tema polêmico e difícil de ser abordado. Esses também não tiveram em sua formação referências, discussões e bibliografia sobre o tema.

Uma das conseqüências da negação da morte, por parte da Universidade e dos professores, é a defasagem na aprendizagem do aluno, pois fica uma lacuna que necessita ser preenchida. Mas é por meio desse questionamento dos alunos que se podem propor mudanças no modo de ensinar, com a oferta de subsídios teóricos e práticos e melhor condição para que os alunos possam cuidar de pessoas à beira da morte, verificando também os seus conteúdos pessoais.

Não acreditar na mudança de postura do curso e dos professores revela a descrença dos alunos quanto à inclusão do tema da morte e morrer. Uma proposta de mudança curricular pode atender essas necessidades, oportunizando aos alunos uma atuação profissional mais eficiente. Esse preparo frente à morte necessita ser construído para que se possa ter a firmeza necessária quando se inicia a prática.
Observa-se um ciclo vicioso que necessita ser modificado. Talvez uma das grandes dificuldades em se lidar com a morte se deva à falta de informação sobre o tema e, principalmente, ao medo do mergulho interior, ocasião em que se busca resolver questões internas com relação ao temor da morte. É importante curar a criança ferida para poder lidar com as dores e as feridas dos outros.

Nesse trabalho com os alunos, chama atenção a forma indignada com que responderam ao questionário, pois sentiam-se lesados pela falta dessa informação. Ao mesmo tempo, parece que também entre eles surge o medo do desconhecido que a questão da morte suscita.

Os resultados mostraram que, no curso de Psicologia da Universidade Federal de Rondônia, os professores têm se omitido a respeito das questões da vida e da morte, como em outros centros de ensino. Seria interessante que houvesse o intercâmbio de informações para que novos cursos fossem criados.

Diante dessas informações, é urgente o debate com os professores sobre essa defasagem presente no curso, abrindo possibilidades de se rever o conteúdo programático das disciplinas bem como a realização de seminários sobre a morte e o morrer. Os alunos ressaltam a necessidade de estudar a morte e o morrer, o que mostra que estão atentos a essa demanda tão urgente.

É importante considerar que, na reformulação da matriz curricular do Curso de Psicologia da Universidade Federal de Rondônia, seja incluída uma disciplina que aborde o tema da morte e do morrer. 


\section{Maria Hercília Rodrigues Junqueira *}

Professora do Departamento de Psicologia da Universidade Federal de Rondônia, Doutora em Psicologia Escolar e do Desenvolvimento Humano pelo Instituto de Psicologia da Universidade São Paulo.

\section{Maria Júlia Kovács **}

Professora Livre-docente do Instituto de Psicologia, Universidade de São Paulo.

\section{Endereço para envio de correspondência:}

* Br 364, Km 9,5 - CEP 78900-000 - Porto Velho/RO.

E-mail: hercília@unir.br

** Av. Mello Moraes, 1721 - CEP 05508-900 - Cidade Universitária - São Paulo - SP.

E-mail: mjkoarag@usp.br

Recebido 11/07/2007 Aprovado 06/07/2008

Ariès, P. (1977). História da morte no Ocidente: da idade média aos nossos dias. Rio de Janeiro: Francisco Alves.

Ariès, P. (1990). O homem diante da morte (Vol. 2). Rio de Janeiro: Francisco Alves.

Bowlby, J. (1985). Perda do cônjuge. In Perda: tristeza e depressão (pp. 83-114). São Paulo: Martins Fontes.

Bromberg, M. H. (1996). Vida e morte: laços da existência. São Paulo: Casa do Psicólogo.

Chizzotti, A. (1998). Pesquisa em ciências humanas e sociais (3a ed.). São Paulo: Cortez.

Crema, R. (2001). Prefácio. In M. Hennezel \& J. Y. Leloup, $A$ arte de morrer: tradições religiosas e espiritualidade humanista diante da morte na atualidade (4a ed.). Petrópolis, RJ: Vozes.

Durlak, J. A., \& Riesenberg, L. A. (1991). The impact of death education. Death Studies, 13, 39-58.

Hennezel, M., \& Leloup, J. Y.(2001). A arte de morrer: tradições religiosas e espiritualidade humanista diante da morte na atualidade (4a ed.). Petrópolis, RJ: Vozes.

Imara, M. (1996). O morrer como último estágio da evolução. In E. Kübler-Ross, Morte: estágio final da evolução (2a ed., p. 195). Rio de Janeiro: Record.

Kastenbaum, R., \& Aisenberg, R. (1983). Psicologia da morte. São Paulo: Pioneira; Novos Umbrais.

Kastenbaum, R., \& Costa, P.(1997). Psychological perspectives on death. Annual Review of Psychology, 28, 225-248.

Kovács, M. J. (2002). Educação para a morte: um desafio na formação de profissionais de saúde e educação. Tese de
Livre Docência, Instituto de Psicologia, Universidade de São Paulo, São Paulo.

Kovács, M. J. (2003). Educação para a morte: desafio na formação de profissionais de saúde e educação. São Paulo: Casa do Psicólogo.

Kovács, M. J. (1996). A morte em vida. In M. H. P. F.Bromberg, M. J. Kovács, M. M. J. Carvalho, \& V. A. Carvalho, Vida e morte: laços da existência (pp. 11-33). São Paulo: Casa do Psicólogo.

Kübler-Ross, E. (1979). Perguntas e respostas sobre a morte e o morrer. São Paulo: Martins Fontes.

Rogers, C. R. (1983). Experiências em comunicação. In R. Rogers, Um jeito de ser (pp. 3-16). São Paulo: EPU.

Rogers, C. R. (1987). Psicoterapia e consulta psicológica. São Paulo: Martins Fontes.

Rogers, C. R. (1989). Sobre o poder pessoal (3a ed.) São Paulo: Martins Fontes.

Rogers,C. R. (1991). Tornar-se pessoa (4a ed). São Paulo: Martins Fontes.

Tonetto, L. M., \& Rech, T. (2001). Lidar com a terminalidade: um desafio para o psicólogo. Psico, 32(1), 5-6.

Weil, P. (1989). A consciência cósmica: introdução à psicologia transpessoal (7a ed.). Petrópolis, RJ: Vozes.

Weil, P. (1995). A morte da morte: uma abordagem transpessoal (7a ed.). São Paulo: Gente.

Zaidhaft, S. (1990). Morte e formação médica. Rio de Janeiro: Francisco Alves. 